\title{
Efficacy of aromatherapy to reduce labor pain
}

\author{
Mark C. Kendall ${ }^{1}$
}

Received: 28 March 2018 / Accepted: 18 June 2018 / Published online: 25 June 2018

c) Springer-Verlag GmbH Germany, part of Springer Nature 2018

\section{Dear Editors,}

I read with great interest the article of Tanvisut et al. in a recent issue of the Journal [1]. The authors performed a randomized controlled trial on 104 patients undergoing labor and concluded that aromatherapy is helpful in reducing pain in latent and early active phase, and may be used as an adjunctive method for labor pain control without serious side effects. The authors should be commended for performing a well-designed study in an important topic (e.g., acute pain) in patients undergoing labor [2, 3]. In addition, the current emphasis on the need to reduce the use of opioids using multimodal analgesic strategies makes the topic very relevant in obstetric medicine $[4,5]$.

The study of Tanvisut et al. was well conducted; however, there are questions regarding the study that need to be clarified to further confirm the author's results. First, it is unclear why the patients did not receive neuraxial analgesia as this is the standard of care to control labor pain in many countries. Second, the aromatherapy group received more meperidine than the control group. It would be important to include meperidine usage and dose in the study analysis as this drug can directly affect the author's main study outcomes. Lastly, the authors evaluated pain at three time periods but did not adjust their analysis to avoid Type I errors.

I would welcome comments to address the aforementioned issues as they were not discussed by the authors as this would further substantiate the findings of this important study.

Author contributions MK: conceptualization, project development, investigation, methodology, project administration, resources, supervision, validation, and manuscript writing.

Funding None.

Mark C. Kendall

mark.kendall@lifespan.org

1 Department of Anesthesiology, Rhode Island Hospital,

Warren Alpert Medical School of Brown University, 593

Eddy Street, Providence, RI 02903, USA

\section{Compliance with ethical standards}

Conflict of interest The author declares no conflicts of interest and nothing to disclose.

Human and animal participant statements This article does not contain any studies with animals or humans performed by any of the authors. This letter is a response to an already published article.

Informed consent Informed consent section was not applicable for this manuscript. This letter is a response to an already published review.

\section{References}

1. Tanvisut R, Traisrisilp K, Tongsong T (2018) Efficacy of aromatherapy for reducing pain during labor: a randomized controlled trial. Arch Gynecol Obstet. https://doi.org/10.1007/s00404-0184700-1 (Epub ahead of print)

2. Dube P, Mitra S, Singh J, Saroa R, Mehra R (2017) Intravenous dexamethasone as an adjunct to improve labor analgesia: a randomized, double-blinded, placebo controlled clinical trial. J Clin Anesth 43:6-10

3. Ferrer LE, Romero DJ, Vásquez OI, Matute EC, Van de Velde M (2017) Effect of programmed intermittent epidural boluses and continuous epidural infusion on labor analgesia and obstetric outcomes: a randomized controlled trial. Arch Gynecol Obstet 296:915-922

4. Zhang Z, Xu H, Zhang Y, Li W, Yang Y, Han T, Wei Z, Xu X, Gao J (2017) Nonsteroidal anti-inflammatory drugs for postoperative pain control after lumbar spine surgery: a meta-analysis of randomized controlled trials. J Clin Anesth 43:84-89

5. Li XD, Han C, Yu WL (2017) Is gabapentin effective and safe in open hysterectomy? A PRISMA compliant meta-analysis of randomized controlled trials. J Clin Anesth 41:76-83 